\title{
Estimated Number of Short-Stay Service Recipients in Hokkaido Prefecture, Japan, from 2020 to 2045: Estimation by Machine Learning and Review of Changing Trend by Cartogram
}

Junko Ouchi ( $\sim$ ouchi-j@hus.ac.jp )

Hokkaido University of Science: Hokkaido Kagaku Daigaku https://orcid.org/0000-0003-0702-2301

Kanetoshi Hattori

Naragakuen University

\section{Research}

Keywords: machine learning, elderly, home care services, forecasting, population forecast

Posted Date: November 9th, 2020

DOl: https://doi.org/10.21203/rs.3.rs-102898/v1

License: (1) This work is licensed under a Creative Commons Attribution 4.0 International License. Read Full License 


\section{Abstract}

Background: For effective allocations of limited human resources, it is significant to have accurate estimates of future elderly care demands at the regional level, especially in areas where aging and population decline vary by region, such as Hokkaido prefecture in Japan.

Objectives: The present study aimed to estimate the numbers of short-stay service recipients in all administrative units in Hokkaido from 2020 to 2045 with the machine learning approaches and reviewed the changing trends of spatial distributions of the service recipients with cartograms.

Methods: A machine learning approach was used for the estimation. To develop the model to estimate, population data in Japan from 2015 to 2017 were used as input signals, whereas data on the numbers of short-stay service recipients at each level of needs for long-term care (levels 15) from 2015 to 2017 were used as a supervisory signal. Three models were developed to avoid problems of repeatability. Then, data of the projected population in Hokkaido every 5 years from 2020 to 2045 were fed into each model to estimate the numbers of the service recipients for the 188 administrative units of Hokkaido. The medians of the estimations from the models were considered as the final results; the estimates for 188 administrative units were presented with continuous area cartograms on the map of Hokkaido.

Results: The developed models predicted that the number of the service recipients in Hokkaido would peak at 18,016 in 2035 and the number of people at level 3 in particular would increase. The cartograms for levels 2 and 3 from 2020 to 2030 and level 3 for 2035 were heavily distorted in the populated areas in Hokkaido.

Discussion: The large correlation coefficients indicated the accuracy of estimations by the developed models. The growing number of the service recipients especially at level 3 by 2035 was assumed to be related to aging of the first baby boomers in Japan. The distortions of the cartograms suggested that the majority of the service recipients would be concentrated in the populated areas in Hokkaido. Future allocations of human resources were discussed on the basis of the findings.

\section{Background}

Japan is a super-aging society with a decreasing population. However, the population in Japan is not aging and decreasing uniformly across the country [1]. Specifically, in Hokkaido, which is the second largest island and northernmost prefecture in Japan, the changes of the population and its composition significantly vary by region. According to the Regional Population Projections for Japan: 2015-2045 [1], the population of Hokkaido is estimated to decrease from 5.22 million in 2020 to 4.01 million in 2045. In addition, it is predicted that the percentage of those at the age of $\geq 65$ years will reach $42.8 \%$ of the total population of Hokkaido in 2045 . The report also suggests that there is a disparity in the changes of population in Hokkaido among the administration units including wards ("Ku"), cities, towns, and villages in Hokkaido. For example, the population of Utashinai City is estimated to decrease from 2884 in 2020 to 813 in 2045, which is only $28.2 \%$ of the population in 2020 . In contrast, the population of the Chuo ward in Sapporo City is estimated to increase from 250,176 in 2020 to 261,704 in 2045 , which is an increase of $104.6 \%$. Thus, although many of areas in Hokkaido have small and declining populations, Sapporo City has an excessive concentration of population and is projected to continue to grow [1].

Because of these characteristics of the population in Hokkaido, planning for the allocations of human resources for nursing care services should be decided on the basis of the future numbers of service recipients at the regional level. In Hokkaido, inadequate human resources in rural areas have long been recognized. Only the Sapporo City area, the most populated area in Hokkaido, and Asahikawa City area, the second most populated area in Hokkaido, have a sufficient number of healthcare workers [2]. To effectively deploy limited human resources, the projected number of service recipients for each region is needed.

Despite its necessity, there is a lack of accurate future estimates of service recipients at the regional level. This problem depends largely on the methodology of estimation. Regression analysis has been used traditionally for such estimation, but its accuracy is not high enough. To pursue more accurate estimates of demands for nursing care services at the regional level, this study utilized a machine learning approach instead of the traditional regression analysis.

Machine learning is a part of artificial intelligence using experience to make accurate predictions or improve performance [3, 4]. It mines for probabilistic relations between the input (i.e., population data) and supervisory (i.e., recipient data) signals. The relations between the input and supervisory signals can be regarded as those of the explanatory and objective variables in traditional statistical analyses. The developed model is a general-purpose estimation model that can be applied to estimate the number of service recipients in any areas of Japan.

The present study estimated the numbers of short-stay service recipients as a proxy of demands for nursing care services. Among various nursing care services provided in Japan, short-stay service plays a significant role as respite care. The service recipients can stay at a facility for a maximum of 30 days. In the meantime, their family caregivers can take a break from caring. In Japan, where home care is promoted, the significance of short-stay services is increasing.

Page 2/11 
Nursing care services are provided according to the levels of care requirements called "Condition of Need for Long-Term Care (CNLTC)" under the long-term care insurance system [5]. CNLTC is divided into five different levels: levels 1-5. Individuals at level 1 need some assistance in activities of daily living but are still being independent in several aspects of daily living. Those at level 2 need partial assistance in activities of daily living, whereas those at level 3 need full assistance in several aspects of daily living. Those at level 4 need more intensive care for all aspects of daily living. Those at level 5 are often bedridden and have difficulties in communication. They need the most intensive care in all aspects of daily living. Recent users of short-stay service have been mainly those at levels 2 and 3 . They account for half of the total users of short-stay service [6].

In sum, this study aimed to estimate the numbers of future recipients of short-stay service in $2020,2025,2030,2035,2040$, and 2045 for all administrative units of Hokkaido using a machine learning approach. Moreover, it reviewed the trends in the changing demands for short-stay service over the next 25 years by presenting the results with cartograms on the map of Hokkaido to consider not only the numbers of service recipients but also their spatial distributions. Finally, issues in effective allocations of human resources for short-stay service in Hokkaido were discussed on the basis of the estimates.

\section{Methods}

\section{Data used for developing a machine learning model}

To develop a machine learning model that can be applicable to estimate the numbers of future short-stay service recipients in any areas of Japan, the population and numbers of short-stay service recipient data are required. The population data of 341 administrative units including 46 prefectures, 20 designated cities, and 45 designated mid-level cities were collected from the Basic Resident Register Population Data of Local Administrations from 2015 to 2017 [7]. Japanese insured individuals aged $\geq 40$ years are qualified to receive short-stay service under the longterm care insurance system. Therefore, the population data of eight groups with 5-year age differences of 40-44, 45-49, 50-54, 55-59, 60-64, $65-69,70-74$, and $\geq 75$ (the sum of values for men and women) were used. Data on the numbers of short-stay service recipients at each CNLTC level for the 341 administrative units of Japan from 2015 to 2017 were collected from government reports, the Survey of Care Service Facilities and Businesses [8-10]. Both datasets are matched by statistical areas: prefectures, designated cities, and designated mid-level cities.

\section{Data processing method}

Among several machine learning models, this study utilized a backpropagation neural network with Predict 3.31 software (NeuralWare) for data processing. A neural network is a computer model whose architecture mimics the knowledge acquisition of the human brain [11]. It consists of interconnected processing elements arranged into input, hidden, and output layers (Fig. 1). The network was trained over a set of input and supervisory signals by adjusting the interconnection weights using a backpropagation algorithm [12].

In this training phase, 171 out of 341 datasets on the numbers of population of eight groups with 5-year age differences were used as input signals (i.e., 40-44, 45-49, 50-54, 55-59, 60-64, 65-69, 70-74, and $\geq 75$ from 2015 to 2017) [7]. Likewise, 171 datasets on the numbers of short-stay service recipients at each CNLTC level [8-10] were used as supervisory signals. The remaining datasets were reserved as testing datasets for cross-validation to evaluate the performance of the developed models. Before dividing the datasets, they were randomized to prevent the arbitrary selection of the training and testing datasets.

As illustrated in Fig. 1, the population data (i.e., input signals) were sequentially input into the backpropagation neural network multiple times while changing the weighted connections between the processing elements until each output from the output layer coincided with the actual numbers of service recipients (i.e., supervisory signals). The calculation stopped when the optimal or quasi-optimal solutions were acquired.

In this study, the training phase was repeated three times to obtain three different models for estimation (i.e., models 1-3) with randomized datasets from the same population. This procedure is required because different outcomes may generate output from the same datasets. The median of the results from the three models was regarded as the final result and expected to rule out outliers and select a robust central tendency.

\section{Validity evaluation of the machine learning model}

After developing the machine learning models, validation was performed with the training datasets to test performance of the developed models. The number of recipients estimated by the machine learning model was compared with the actual number of recipients (i.e., supervisory signal) via the correlation coefficient. Additionally, a cross-validation was performed by applying the same machine learning models to the remaining 170 testing datasets. Table 1 shows the outcomes of the validation and cross-validation of levels 1-5. Large correlation coefficients were observed for each developed model. The usage of the models was found appropriate for the future prediction of the number of recipients. 
Table 1

Correlation coefficients between actual and estimated numbers of short-stay service recipients at CNLTC level

\begin{tabular}{|c|c|c|c|c|c|c|c|c|c|c|}
\hline & Level 1 & & Level 2 & & Level 3 & & Level 4 & & Level 5 & \\
\hline & Validation & $\begin{array}{l}\text { Cross- } \\
\text { validation }\end{array}$ & Validation & $\begin{array}{l}\text { Cross- } \\
\text { validation }\end{array}$ & Validation & $\begin{array}{l}\text { Cross- } \\
\text { validation }\end{array}$ & Validation & $\begin{array}{l}\text { Cross- } \\
\text { validation }\end{array}$ & Validation & $\begin{array}{l}\text { Cross- } \\
\text { validation }\end{array}$ \\
\hline $\mathrm{N}$ & 171 & 170 & 171 & 170 & 171 & 170 & 171 & 170 & 171 & 170 \\
\hline $\begin{array}{l}\text { Model } \\
1\end{array}$ & .94 & .92 & .94 & .94 & .95 & .93 & .94 & .89 & .93 & .89 \\
\hline $\begin{array}{l}\text { Model } \\
2\end{array}$ & .95 & .90 & .94 & .91 & .97 & .94 & .88 & .84 & .93 & .93 \\
\hline $\begin{array}{l}\text { Model } \\
3\end{array}$ & .96 & .95 & .97 & .94 & .95 & .90 & .95 & .87 & .95 & .89 \\
\hline
\end{tabular}

\section{Estimation of future service recipients in Hokkaido}

After the successful development of the machine learning models, these models were applied to estimating the number of short-stay service recipients in 188 administrative units in Hokkaido. For the estimation, projected population data of wards, cities, towns, and villages of Hokkaido at every 5 years from 2020 to 2045 reported in the Regional Population Projections for Japan: 2015-2045 [1] were used. The dataset of this report area also organized with eight groups with 5 -year age differences, that is, aged $\geq 40$ years. Calculations were conducted by the three developed models (models 1-3) for each of the years. The median of the three estimates from the three models was the final result at each level for a given year.

\section{Continuous Area Cartogram}

To review the results, continuous area cartograms were created for the estimated numbers of short-stay service recipients in Hokkaido at each level of the CNLTC from 2020 to 2045. Area cartogram is a type of cartogram developed by Gastner and Newman [13]. It is considered as a very effective technique for the visualization of spatial data [14]. Geographical areas are changed proportional to the attributed value. In this study, the administrative units in Hokkaido were resized in proportion to the estimated numbers of service recipients. Cartogram 3 plugin of QGIS 3.14.0 $\mathrm{Pi}[15]$ was used.

\section{Results}

\section{Estimated numbers of short-stay service recipients from 2020 to 2045}

The estimated numbers of short-stay service recipients for 188 administrative units including 10 wards of Sapporo City, 34 cities, 128 towns, and 16 villages from 2020 to 2045 by the machine learning models are presented in Appendix Tables 1-1-1-6 in Additional file 1.

\section{Continuous area cartograms for each level of CNLTC from 2020 to 2045}

The cartograms for the estimated numbers of future short-stay service recipients at each CNLTC level for 188 administrative units in Hokkaido from 2020 to 2045 are presented in Fig. 2 As illustrated in the cartogram for the level 1 in 2020, there are areas with darker colors indicating larger estimated numbers of service recipients. Area A consists of the wards of Sapporo City and its surrounding cities including Otaru, Ishikari, Ebetsu, Eniwa, Chitose, Kitahiroshima, and Iwamizawa. Areas B-F are Tomakomai City, Hakodate City, Asahikawa City, Obihiro City, and Kitami City, respectively. Area G is separated into two parts, but both are Kushiro City. Those areas correspond to the population centers in Hokkaido. The estimated numbers of short-stay service recipients for those areas as well as the rest of areas are presented in Table 2. 
Table 2

Summary of the estimated numbers of short-stay service recipients in Hokkaido from 2020 to 2045

\begin{tabular}{|c|c|c|c|c|c|c|c|}
\hline & & Level 1 & Level 2 & Level 3 & Level 4 & Level 5 & Total \\
\hline \multirow[t]{10}{*}{2020} & All areas & 2746 (19.6) & 3785 (27.0) & $3287(23.5)$ & 1961 (14.0) & 2229 (15.9) & 14008 \\
\hline & Area $A$ to $G$ & 1579 & 2177 & 1934 & 1355 & 1260 & 8305 (59.3) \\
\hline & Others & 1167 & 1608 & 1353 & 606 & 969 & 5703 (40.7) \\
\hline & Area A & 980 & 1398 & 1202 & 844 & 810 & 5234 \\
\hline & Area B & 87 & 105 & 75 & 59 & 41 & 367 \\
\hline & Area C & 97 & 151 & 127 & 100 & 101 & 576 \\
\hline & Area D & 183 & 212 & 238 & 164 & 125 & 922 \\
\hline & Area E & 80 & 107 & 90 & 54 & 61 & 392 \\
\hline & Area $\mathrm{F}$ & 70 & 84 & 114 & 60 & 59 & 387 \\
\hline & Area G & 82 & 120 & 88 & 74 & 63 & 427 \\
\hline \multirow[t]{10}{*}{2025} & All areas & 3091 (17.9) & 3917 (22.7) & $4421(25.7)$ & 2799 (16.2) & $3002(17.4)$ & 17230 \\
\hline & Area $A$ to $\mathrm{G}$ & 1811 & 2586 & 3222 & 1941 & 2266 & $11826(68.6)$ \\
\hline & Others & 1280 & 1331 & 1199 & 858 & 736 & 5404 (31.4) \\
\hline & Area A & 1166 & 1737 & 2193 & 1302 & 1636 & 8034 \\
\hline & Area B & 72 & 121 & 93 & 74 & 80 & 440 \\
\hline & Area C & 135 & 180 & 302 & 203 & 162 & 982 \\
\hline & Area D & 196 & 230 & 271 & 150 & 165 & 1012 \\
\hline & Area E & 87 & 111 & 110 & 75 & 71 & 454 \\
\hline & Area $\mathrm{F}$ & 60 & 85 & 95 & 47 & 57 & 344 \\
\hline & Area G & 95 & 122 & 158 & 90 & 95 & 560 \\
\hline \multirow[t]{10}{*}{2030} & All areas & 2067 (11.5) & 3477 (19.4) & 6075 (33.9) & $2894(16.2)$ & 3396 (19.0) & 17909 \\
\hline & Area $A$ to $G$ & 1997 & 2705 & 4389 & 2516 & 2700 & 14307 (79.9) \\
\hline & Others & 70 & 772 & 1686 & 378 & 696 & $3602(20.1)$ \\
\hline & Area A & 1355 & 1860 & 3220 & 1845 & 1942 & 10222 \\
\hline & Area B & 69 & 117 & 233 & 106 & 208 & 733 \\
\hline & Area C & 135 & 180 & 302 & 203 & 162 & 982 \\
\hline & Area D & 196 & 230 & 271 & 150 & 165 & 1012 \\
\hline & Area $\mathrm{E}$ & 87 & 111 & 110 & 75 & 71 & 454 \\
\hline & Area $\mathrm{F}$ & 60 & 85 & 95 & 47 & 57 & 344 \\
\hline & Area G & 95 & 122 & 158 & 90 & 95 & 560 \\
\hline \multirow[t]{8}{*}{2035} & All areas & 2021 (11.2) & 3299 (18.3) & $6674(37.0)$ & 3183 (17.7) & 2839 (15.8) & 18016 \\
\hline & Area $A$ to $\mathrm{G}$ & 1699 & 2565 & 4581 & 2637 & 1900 & $13382(74.3)$ \\
\hline & Others & 322 & 734 & 2093 & 546 & 939 & 4634 (25.7) \\
\hline & Area A & 1200 & 1804 & 3163 & 1922 & 1286 & 9375 \\
\hline & Area B & 70 & 125 & 222 & 150 & 99 & 666 \\
\hline & Area C & 89 & 143 & 289 & 93 & 116 & 730 \\
\hline & Area D & 150 & 207 & 394 & 178 & 167 & 1096 \\
\hline & Area E & 70 & 116 & 189 & 142 & 91 & 608 \\
\hline
\end{tabular}




\begin{tabular}{|c|c|c|c|c|c|c|c|}
\hline & Area F & 52 & 71 & 125 & 68 & 58 & 374 \\
\hline & Area G & 68 & 99 & 199 & 84 & 83 & 533 \\
\hline \multirow[t]{10}{*}{2040} & All areas & $2562(21.3)$ & $2896(24.0)$ & 3351 (27.8) & 2129 (17.7) & $1115(9.3)$ & 12053 \\
\hline & Area A to G & 1802 & 1953 & 2842 & 1656 & 1035 & $9288(77.1)$ \\
\hline & Others & 760 & 943 & 509 & 473 & 80 & 2765 (22.9) \\
\hline & Area A & 1217 & 1375 & 2092 & 1181 & 772 & 6637 \\
\hline & Area B & 57 & 73 & 112 & 74 & 49 & 365 \\
\hline & Area C & 138 & 109 & 121 & 89 & 51 & 508 \\
\hline & Area D & 180 & 185 & 237 & 131 & 65 & 798 \\
\hline & Area E & 57 & 78 & 112 & 76 & 45 & 368 \\
\hline & Area $\mathrm{F}$ & 60 & 58 & 80 & 43 & 21 & 262 \\
\hline & Area G & 93 & 75 & 88 & 62 & 32 & 350 \\
\hline \multirow[t]{10}{*}{2045} & All areas & $2235(20.2)$ & $2904(26.2)$ & 3039 (27.5) & $1854(16.8)$ & 1033 (9.3) & 11065 \\
\hline & Area $A$ to $G$ & 1988 & 2226 & 2359 & 1355 & 822 & $8750(79.1)$ \\
\hline & The others & 247 & 678 & 680 & 499 & 211 & 2315 (20.9) \\
\hline & Area A & 1387 & 1589 & 1691 & 953 & 606 & 6226 \\
\hline & Area B & 87 & 102 & 102 & 68 & 36 & 395 \\
\hline & Area C & 111 & 115 & 135 & 81 & 40 & 482 \\
\hline & Area D & 179 & 178 & 171 & 98 & 48 & 674 \\
\hline & Area E & 92 & 108 & 123 & 61 & 46 & 430 \\
\hline & Area F & 57 & 59 & 55 & 37 & 18 & 226 \\
\hline & Area G & 75 & 75 & 82 & 57 & 28 & 317 \\
\hline
\end{tabular}

\section{Discussion}

The present study estimated the number of future short-stay service recipients by the CNLTC level from 2020 to 2045 using the machine learning approach. The large correlation coefficients between the estimated and actual numbers of short-stay service recipients suggest high accuracy of the estimates obtained by the machine learning processes in this study. This indicates that machine learning estimation can be an effective approach to estimate the number of nursing care service recipients in an area of Japan. Based on the estimates obtained and the cartograms, the changing trends of the numbers and spatial distributions of short-stay service recipients in Hokkaido were reviewed. Additionally, issues in future human resource allocations for the service were discussed.

\section{Changing trends of the numbers of short-stay service recipients}

As shown in Table 2, the total estimated number of short-stay service recipients reaches 18,016 in 2035 and then starts to decline even though the whole population of Hokkaido is constantly decreasing. The estimated number for 2045 is 11,065 , which is $61 \%$ of that for 2035 . Such change in the estimated numbers can be attributed to the aging of those born during the first baby boom from 1947 to 1949 in Japan.

Among the five CNLTC levels, the estimates suggest that those at levels 2 and 3 are the main users of short-stay service. The estimated numbers for levels 2 and 3 accounts for more than half of the total estimated numbers for each year. Such trend is the same as the present situation. There can be more need for short-stay service in those at level 2 or 3 compared with those at level 1 who are more independent as well as those at levels 4 and 5 who may choose facility care service.

In particular, there is a significant increase in the estimated number of the service recipients at level 3 in the years 2030 and 2035 . Moreover, the proportion of the service recipients at level 3 is estimated to increase to $>30 \%$ of the total in 2030 and 2035, whereas the proportion of those at 
level 1 decreases. These results can also be associated with aging of the first baby boomers. In 2035 , the first baby boomers will be approximately 85 years old in Japan. Consequently, the number of the elderly people who need assistance with all aspects of daily living and could be categorized in level 3 will probably increase in that year. However, in 2040 and 2045, the percentage of people at level 3 is predicted to decrease, whereas that of people at level 1 is predicted to increase. This may be due to the transaction of the main service recipients from the first baby boomers to the next younger generation.

\section{Changes of spatial distributions of short-stay service recipients}

As the areas with darker colors in all the cartograms (Fig. 2) indicate, service recipients are concentrated in areas A-G, which are the high population centers in Hokkaido from 2020 to 2045. In particular, from 2020 to 2030, area A is significantly expanded especially in the cartograms for levels 2 and 3. In addition, areas B-G are also expanded according to the estimated numbers although not as much as area A. Consequently, the maps for levels 2 and 3 from 2020 to 2030 are heavily distorted. These suggest that most of future short-stay service recipients are greatly concentrated in the population centers, especially in the area of Sapporo City and its surrounding cites (area A), from 2020 to 2030 . Such concentration of the service recipients is also illustrated in Table 2. Nearly $80 \%$ of the estimated service recipients are concentrated in areas $A-G$ from 2030 to 2045 .

In 2035, however, only the cartogram for level 3 shows the same concentrations of the service recipients as those in the earlier years, reflecting an increase of the numbers of recipients at level 3. Actually, as shown in Table 2, in 2035, compared with 2030, the estimated number of recipients at level 3 increases from 6075 to 6674 , whereas that of level 2 decreases from 3477 to 3299.

In 2040 and 2045, service recipients are still concentrated in the populated areas highlighted with darker colors. However, as the cartograms for those years with fewer distortions suggest, excessive concentrations of the service recipients in area A are not predicted in 2040 and 2045 at any level of the CNLTC. The main reason for this is the significant decline in the estimated number of the service recipients at level 3 in 2040 and 2045 as noted earlier.

\section{Issues for future resource allocations based on the estimates}

On the basis of the results of the estimations, there are three issues for the effective allocations of human resources for future short-stay services in Hokkaido. The first one is the allocation of adequate human resources to the areas where the service recipients are estimated to be concentrated. This study predicted that the service recipients would heavily concentrate in the Sapporo area. Although there has been a high concentration of healthcare workers in the Sapporo area, it should be examined whether that will be sufficient in the future as well. Moreover, in the other areas where the service recipients were also estimated to be concentrated, there may be a shortage of personnel. It is necessary to take measure to spread the human resources concentrated in the Sapporo area to the other areas in Hokkaido. For future discussions, the accurate estimates of care supplies are also required in addition to the estimates of care demands.

The second challenge is to ensure that there are sufficient personnel to meet the increase in the number of the service recipients at level 3 in 2030 and 2035. Those at level 3 need more assistance than those at levels 1 and 2 . Compared with those at level 2, more personnel may be needed to provide those at level 3 with quality care. As the cartograms for level 3 illustrate, the increase in the number of those at level 3 is significant in the Sapporo area. This means that the Sapporo area must deploy human resources to meet the growing number of service recipients who need more care by 2030 .

The third one is a possibility of severe staff shortages in 2040 and 2045 . Although it is predicated that the total number of the service recipients will drop to $61 \%$ of those in 2035 , it is still a possibility for severe staff shortages in 2040 and 2045 . It is projected that people aged $\geq 65$ years will account for $40 \%$ of the population in those years in Hokkaido. This indicates a significant decline in the working population. To overcome this challenge, the use of technologies including robots and artificial intelligence has been examined [16-19]. However, such technologies have been rarely used in nursing care for elderly people in Japan [20]. Ishiguro [20] suggests that a lack of adoption of care robots to nursing care settings is due to a belief that human hands should undertake care in Japan as well as a lack of information about such technologies among healthcare and care workers. Future studies must tackle not only technological issues but also those in the improvements of accepted modern associative technologies of care among the general people and those in nursing care services.

\section{Limitations Of The Present Study}

Despite the accurate estimates obtained in this study, there are no estimates for care supplies. The machine learning approach can be applied to project the number of workers in nursing care services as a proxy of care supplies. Future studies should examine the changes of demands as well as supplies of nursing care services estimated by the machine learning approaches. 


\section{Conclusions}

The present study estimated the numbers of future short-stay service recipients in Hokkaido, Japan, from 2020 to 2045 using the machine learning approaches. The large correlation coefficients between the estimated and actual numbers of the service recipients indicated the accuracy of estimations by the developed models. The models predicted that the number of the service recipients in Hokkaido would peak at approximately 18,000 in 2035 and the number of people at level 3 of the CNLTC in particular would increase. The models also predicted that from 2020 to 2045, the majority of the service recipients would be concentrated in the populated areas in Hokkaido, especially in the Sapporo area. The future allocation of human resources needs to meet demands from these changes.

\section{Abbreviations}

CNLTC: Condition of Need for Long-Term Care

\section{Declarations}

\section{Acknowledgement}

The authors would like to thank MARUZEN-YUSHODO Co., Ltd. for the English language editing.

\section{Authors' contributions}

JO designed the study, interpreted data, and wrote the first draft. $\mathrm{KH}$ designed the study, did the machine learning, and wrote the drafts. Both authors read and approved the final manuscript.

\section{Availability of data and materials}

Links to all data generated or analyzed during this study are included in this published article.

\section{Competing interests}

The authors declare that they have no competing interests.

\section{Ethics approval and consent to participants}

Not applicable.

\section{Consent for publication}

Not applicable.

\section{Funding}

Not applicable.

\section{Ethical Conduct of Research}

This study was not reviewed by the IRB because it was based on publicly available statistical data.

\section{Clinical Trial Registration}

This is required for this study.

\section{References}


1. Regional Population Projections for Japan. 2015-2045 [Internet]. National Institute of Population and Social Security Research; c 2018 [cited 2020 June 06]. Available from: http://www.ipss.go.jp /pp-shicyoson/e/shicyoson18/t-page.asp.

2. Hokkaido Medical Plan. for 2018-2023 [Internet]. Hokkaido Department of Health and Welfare; c 2020 [cited 2020 September 06]. Available from: http://www.pref.hokkaido.lg.jp/hf/cis/iryokeikaku/ aratanairyoukeikaku.htm.

3. Alpaydin E. (2020). Introduction to machine learning. MIT press.

4. Hattori K, Hattori R. Number of pregnant women in Aichi prefecture, Japan, estimated by machine learning: Database Construction for Disaster Preparation. Disaster Medicine and Public Health Preparedness (under review).

5. Overview of Public Long-Term Care Insurance [Internet]. Ministry of Health, Labour \& Welfare; c 2018 [cited 2020 September 06]. Available from https://www.mhlw.go.jp/content/0000213177.pdf.

6. Short-term Institutional Living Care and Short-term care. Institutional Nursing Ministry of Health, Labour \& Welfare; c 2017 [cited 2020 September 01]. Available from https://www.mhlw.go.jp /file/05-Shingikai-12601000-SeisakutoukatsukanSanjikanshitsu_ Shakaihoshoutantou /0000168704.pdf.

7. Basic Resident Register Population Data of Local Administrations [Internet]. Ministry of Internal Affairs and Communications; c 2020 [cited 2020 June 06]. Available from https://www.e-stat.go.jp/stat-search/files? page $=1$ \&layout $=$ datalist \&toukei=00200241\&tstat $=\% 20000001039591 \&$ cycle $=7 \&$ tclass $1=000001039601$.

8. Goh AT. Back-propagation neural networks for modeling complex systems. Artif Intell Eng. 1995;9(3):143-51.

9. Fogel DB, Fogel LJ, Porto VW. Evolving neural networks. Biol Cybern. 1990;63(6):487-93.

10. Gastner MT. Newman MEJ. Diffusion-based method for producing density-equalizing maps, PNAS 2004;101(20), 7499 - 504. https://doi.org/10.1073/pnas.0400280101.

11. Sun H, Li Z. Effectiveness of cartogram for the representation of spatial data. Cartographic Journal. 2010;47(1):12-21. https://doi.org/10.1179/000870409X12525737905169.

12. QGIS (Version. 3.14.0 Pi) [Computer software]. Open Source Geospatial Foundation c 2020 [downloaded 2020 June 22]. Available from https://qgis.org/downloads/.

13. Bemelmans R, Gelderblom GJ, Jonker P, De Witte L. Socially assistive robots in elderly care: A systematic review into effects and effectiveness. JAMDA. 2012;13(2), 114-20. https://doi.org/10.1016/j.jamda. 2010.10.002.

14. Lee JY, Song YA, Jung JY, Kim HJ, Kim BR, Do HK, Lim JY. Nurses' needs for care robots in integrated nursing care services. J Adv Nurs. 2018;74(9):2094-105. https://doi.org/10.1111/jan.13711.

15. Wada K, Shibata T. Living with seal robots-its sociopsychological and physiological influences on the elderly at a care house. IEEE Trans Rob, 2007;23(5), 972 - 80. https://doi:10.1109/TR0.2007.906261.

16. Wang Z, Yang Z, Dong T. A review of wearable technologies for elderly care that can accurately track indoor position, recognize physical activities and monitor vital signs in real time. Sensors. 2017;17(2):341. https://doi.org/10.3390/s17020341.

17. Ishiguro N. Care robots in Japanese elderly care. Cultural values in focus. In: Christensen K, Pilling D, editors. The Routledge Handbook of Social Care Work. around the World: Routledge; 2017. pp. 256-69.

18. Wada K, Shibata T. Living with seal robots-its sociopsychological and physiological influences on the elderly at a care house. IEEE Transactions on Robotics, 2007;23(5), 972 - 80. https://doi: 10.1109/TRO.2007.906261

19. Wang Z, Yang Z, Dong, T. A review of wearable technologies for elderly care that can accurately track indoor position, recognize physical activities and monitor vital signs in real time. Sensors, 2017;17(2), 341. https://doi.org/10.3390/s17020341

20. Ishiguro N. Care robots in Japanese elderly care. Cultural values in focus. In Christensen K, Pilling D, editors. The Routledge Handbook of Social Care Work around the World: Routledge; 2017;256-269.

\section{Figures}




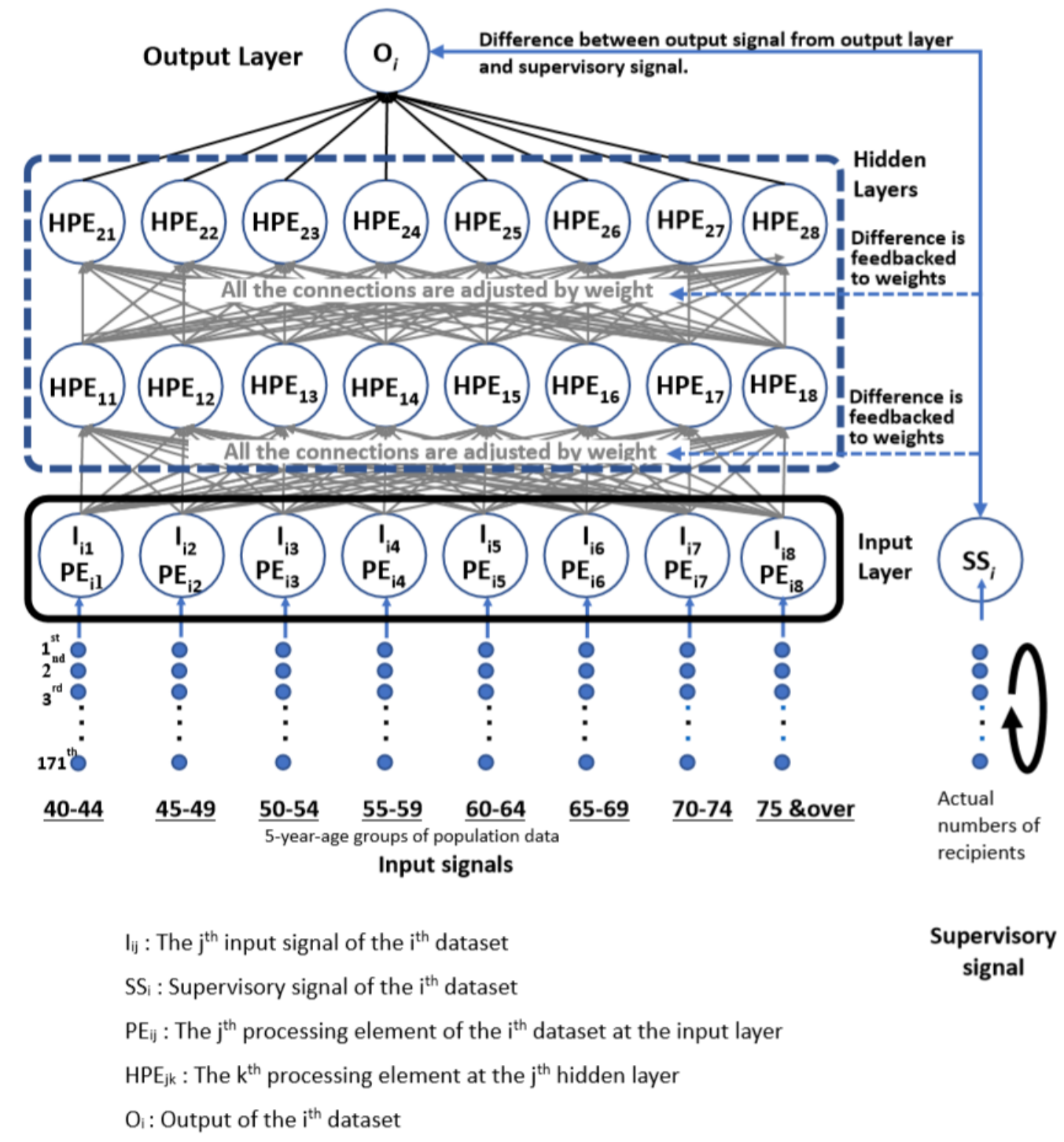

Figure 1

Data processing with a backpropagation neural network. In an input layer, data are taken into the neural network; an output layer holds the network response to the input. Hidden layers are where the data are proceeded in the network. 


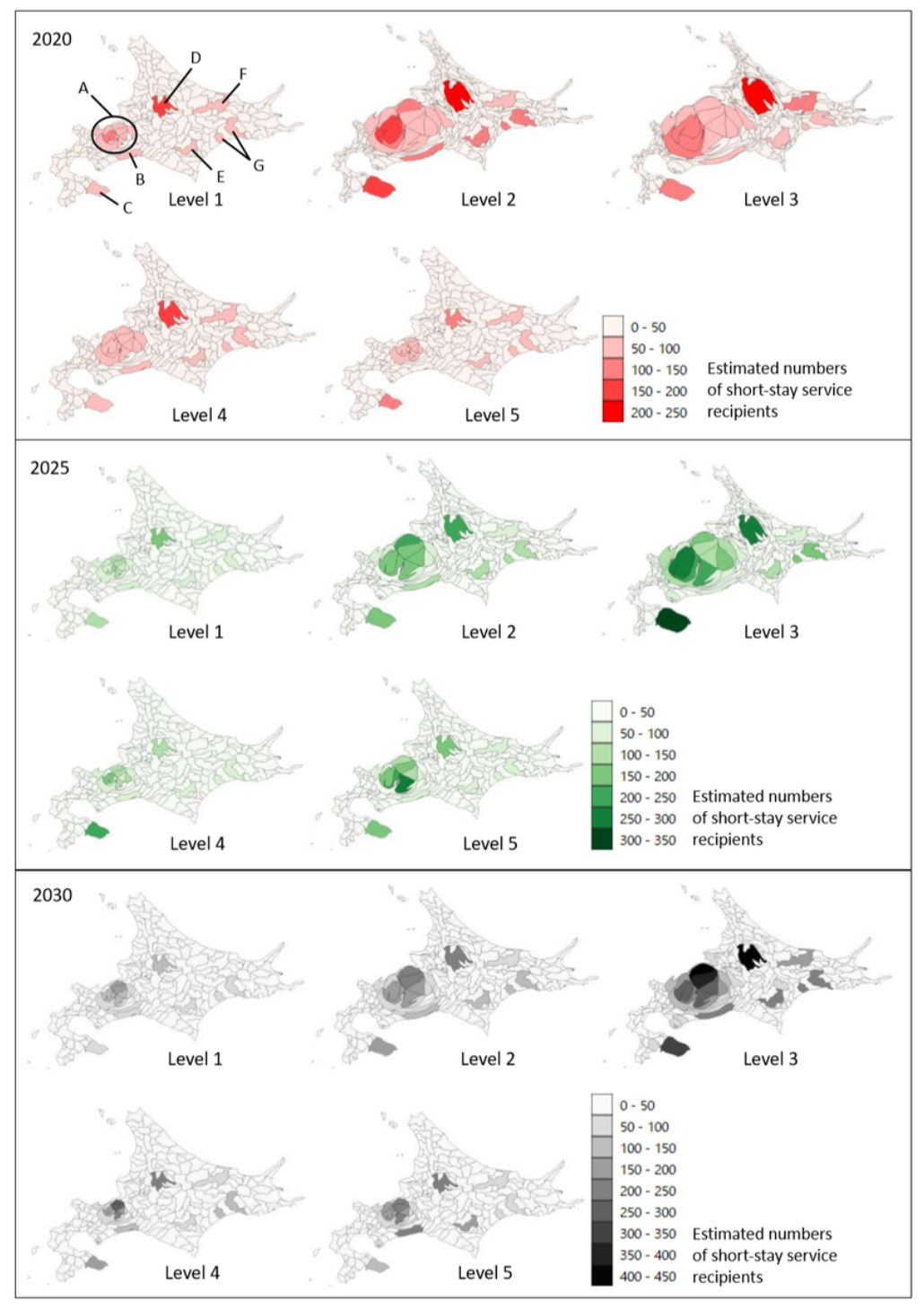

Figure 2

Cartograms of the estimated numbers of short-stay service recipients in Hokkaido from 2020 to 2045

\section{Supplementary Files}

This is a list of supplementary files associated with this preprint. Click to download.

- AppendixMLHRH021120.docx 